\title{
Estrategias institucionales en torno a Bibliografia de arte colonial argentino, de Mario Buschiazzo (1947)*
}

\section{Institutional strategies concerning Bibliography of Argentinean Colonial Art by Mario Buschiazzo (1947)}

\author{
Carla Guillermina García \\ cgarciaolivieri@filo.uba.ar \\ Becaria doctoral (CONICET) \\ Instituto de Teoría e Historia del Arte "Julio E. Payró" \\ 25 de Mayo $2214^{\circ}$ piso \\ 1002 - Ciudad Autónoma de Buenos Aires \\ Argentina
}

\begin{abstract}
Resumen
En este trabajo se analiza el libro Bibliografía de arte colonial argentino (BUSCHIAZZO, 1947) al interior del proceso de institucionalización y consolidación disciplinar de los estudios sobre arte colonial en la Argentina dentro del ámbito universitario. A partir del análisis de la especificidad de su formato en el contexto historiográfico de la época, se sostiene que el libro tuvo un rol estratégico en la reorientación de los estudios artísticos propuesta por el Instituto de Arte Americano e Investigaciones Estéticas (IAA) en la Universidad de Buenos Aires. Además de servir de soporte a las aspiraciones profesionales perseguidas por su autor, expresadas en el ejercicio de la crítica bibliográfica, el libro constituyó un formato efectivo hacia la escena local y transnacional para la consolidación de su perfil de especialista, en el mismo momento en que lograba establecer su propio espacio de producción historiográfica.
\end{abstract}

\section{Palabras clave}

Historia del arte y de la arquitectura; Historiografía argentina; Historia de las instituciones.

\begin{abstract}
This paper analyzes the book Bibliography of Argentinean Colonial Art (Mario Buschiazzo, 1947) regarding the process of institutionalization and consolidation of colonial art studies at the University of Buenos Aires. Following the specificities of its format in the historiographical context of the period, I sustain that the book had a strategic role in the reorientation of artistic studies proposed by the mentioned university's Institute of American Art and Aesthetic Studies. Besides professional aspirations pursued by its author, expressed in the exercise of the bibliographical review, the book constituted an effective format for the local and transnational scene regarding the consolidation of Buschiazzo's profile as an expert, establishing his own historiographical production space.
\end{abstract}

Keywords

Art history, History of architecture; Argentinean historiography; History of institutions.

Recibido el: 21/10/2016

Aceptado el: 5/6/2017

\footnotetext{
* Una versión preparatoria de este trabajo fue leída en el IV Congreso Internacional Artes en Cruce, realizado en abril de 2016 en la Facultad de Filosofía y Letras de la Universidad de Buenos Aires. Agradecemos a la familia Buschiazzo, al Instituto de Arte Americano y a la Academia Nacional de Bellas Artes por el acceso a los documentos aquí citados.
} 
Este artículo se inscribe en una investigación doctoral en curso orientada a explicitar la consolidación de los estudios artísticos en la Argentina. Nuestro principal objeto de estudio es el Instituto de Arte Americano e Investigaciones Estéticas (IAA), creado en la Universidad de Buenos Aires durante el año de 1946 bajo la conducción del arquitecto argentino Mario Buschiazzo (1902-1970). El proyecto estudia la historia de la historiografía artística priorizando su dimensión institucional y aquello que, en términos de Michel de Certeau, constituye un lugar de producción ligado al ejercicio de una profesión y al establecimiento de determinados métodos (DE CERTEAU 2008).

Ubicado como continuador en Sudamérica de una tradición institucional reconocible dentro del ámbito transnacional, representada por el Laboratorio de Arte de la Universidad de Sevilla y el Instituto de Investigaciones Estéticas de la Universidad Nacional Autónoma de México (UNAM), ${ }^{1}$ el IAA marcó un punto de inflexión en la historiografía artística argentina al consolidar el desarrollo de los estudios sobre arte en el contexto universitario. Principalmente, se destacó su papel en el afianzamiento de una perspectiva científica centrada en la recuperación y en el análisis de las fuentes documentales (BURUCUA; TELESCA 1996, BURUCUA 1999, GORELIK; SILVESTRI 1990), lectura que priorizó su dimensión metodológica ligándolo al "proyecto global de la Nueva Escuela Histórica" (BURUCUA; TELESCA 1996, p. 237); sin embargo, no avanzó sobre su potencialidad crítica dentro del contexto historiográfico local ni en su demanda de especialización disciplinar sobre la producción escrita en arte y en arquitectura. Fue justamente mediante los proyectos editoriales liderados por Buschiazzo que se plasmó una propuesta renovadora que incluyó la valoración crítica de la bibliografía precedente y contemporánea.

El primer libro orientado en ese sentido, y al mismo tiempo el primer libro del IAA, fue Bibliografía de arte colonial argentino (BUSCHIAZZO 1947). Escasamente mencionado por la historia de la historiografía, la publicación posee un valor particular por el formato elegido y por el carácter programático que encierra su prólogo, donde el autor elabora una crítica a los estudios del área e insta a nuevas líneas de análisis necesarias al interior del nuevo espacio académico. En este artículo consideramos a Bibliografía... como principal punto de partida de la renovación historiográfica sostenida por Buschiazzo; recuperamos sus principales antecedentes y examinamos cuestiones relativas a la especificidad de su formato, a la revisión del lugar del arte argentino en relación con otros virreinatos de la América colonial y a las intervenciones del autor sobre los escritos del área.

A partir de ese acercamiento, entendemos que la elección de Bibliografía... como publicación inaugural del IAA respondió a estrategias de inserción en el campo historiográfico local y transnacional a partir del ejercicio de la crítica bibliográfica y que procuraban otorgar una plataforma a una propuesta institucional orientada a proyectos editoriales basados en la búsqueda de rigor

\footnotetext{
${ }^{1}$ El Instituto mexicano se creó como laboratorio de la mano de Manuel Toussaint en 1935 y luego se constituyó como instituto dentro de la UNAM, en 1936. En su primera instancia fue apadrinado por el Laboratorio sevillano, liderado por Diego Angulo Iñiguez.
} 
científico. En este marco, entendemos la noción de estrategia a partir de la distinción establecida por De Certeau respecto de las tácticas: mientras estas últimas no cuentan con un lugar propio ni con "una base donde capitalizar sus ventajas" (DE CERTEAU 2000, p. LI), la estrategia "postula un lugar susceptible de circunscribirse como un lugar propio y luego servir de base a un manejo de sus relaciones con una exterioridad distinta," como modelo estratégico propio, en este caso, de la racionalidad científica. Este señalamiento nos resulta pertinente para destacar la posición que Buschiazzo comenzó a ocupar desde la creación del IAA, al diferenciarse de organismos ligados a entes oficiales como las Academias nacionales, y desde un lugar diferencial y reconocible en tanto creador del primer centro de estudios artísticos desde la universidad. Tras su renuncia a la Comisión Nacional de Museos y de Monumentos en 1947, en la cual había participado como arquitecto asesor en restauraciones de importantes edificios históricos, su carrera se centró en la docencia y en la investigación. Desde 1941 fue profesor titular de Historia de la Arquitectura (segundo curso) en la Universidad de Buenos Aires y la creación del IAA afianzó su vinculación con la universidad como espacio de producción historiográfica. ${ }^{2}$

\section{Postulados de una renovación historiográfica desde el IAA}

La revista Anales fue la publicación más reconocida del IAA y, desde allí, su director sostuvo el objetivo de estudiar y divulgar el arte del período colonial convocando en sus páginas a profesionales de América y de Europa 12 en un ciclo prolongado entre los años de 1948 y $1971 .^{3}$ En el análisis de esa publicación y, más precisamente, de su "Presentación", se subrayó el espíritu polémico que presentó desde sus inicios (PENHOS 2005). En dicho prólogo, Buschiazzo exponía una crítica a los estudios del área, ubicándolos en una época pretérita que calificaba como "romántica", a la vez que establecía "la labor precisa, documentada, metódica de las nuevas generaciones" (EL DIRECTOR 1948, p. 6) como horizonte de expectativas que determinaría el proyecto de Anales desde ese momento. Por dos motivos podemos afirmar que ese texto constituye un hito para la historiografía artística: primero, por evidenciar la falta de especialización en la divulgación de los escritos sobre arte, que ocupaban espacios parciales dentro de los boletines de historia o se encontraban sujetos a formatos enciclopédicos; y, segundo, por señalar la necesidad de un formato académico de divulgación al mismo tiempo en que Anales se postulaba como tal.

Sin embargo, la publicación de Bibliografía... debería ser considerada como un precedente de mayor importancia. Su singularidad como primera publicación del IAA acompañó su función como principal soporte del proyecto institucional que se estaba iniciando y del plan editorial que comenzaba a perfilarse. Al

\footnotetext{
2 Por otro lado, sus ingresos a la Academia Nacional de Bellas Artes y a la Academia Nacional de la Historia se vieron demorados por su enfrentamiento con Martín Noel; recién tras haber fallecido este, en 1963, Buschiazzo pudo acceder simultáneamente como miembro en ambos organismos.

${ }^{3}$ El n. 24 fue el último publicado luego de la muerte de Buschiazzo en 1970. Retomó su aparición en 1987 y continúa hasta la actualidad.
} 
mismo tiempo, se trató de una sistematización inédita de los escritos sobre arte colonial argentino (véase GEOGHEGAN 1965; ZABALA; FERNANDEZ 2000) y de organización de sus áreas de pertenencia (arquitectura, artes menores, pintura, etc.). Esta orientación se tornaba programática en la "Advertencia preliminar" de Bibliografía..., que a modo de prólogo sostenía un enlace con el proyecto institucional. Su propósito inicial se dirigía a "poner un poco de orden" (BUSCHIAZZO 1947, p. VII) sobre la producción escrita relacionada con las artes en Argentina hasta ese momento, dada la dispersión dominante del material en cuestión, repartido en diversos formatos como libros, folletos, y artículos. A la falta de especialización como problema, se sumaba el descrédito sobre el carácter poco científico de dichos abordajes:

La deficiencias que se notan en nuestra producción obedecen muchas veces a falta de rigorismo científico, defecto propio de un país de cultura en formación, y en otras ocasiones, acaso las más, a la dificultad de conocer y conseguir las fuentes directas o indirectas que deben consultarse para toda labor seria (BUSCHIAZZO 1947, p. VII).

De este modo, el libro venía a intervenir en una coyuntura desfavorable a la especialización anhelada por Buschiazzo, organizando el conjunto del material disponible con vistas a facilitar la emergencia de nuevas investigaciones. Aunque Buschiazzo sugería que la elaboración del libro había resultado antes del establecimiento del IAA, ${ }^{4}$ en el prólogo se encargaba de articular su importancia como espacio apropiado para la promoción y producción de conocimiento y que ocupaba un lugar hasta ese momento "ausente en el cuadro de nuestra organización cultural" (BUSCHIAZZO 1947, p. IX). Se ubicaba de ese modo, en una tradición institucional que sostenía un programa editorial especializado en arte hispanoamericano dentro del ámbito universitario, más precisamente los antes mencionados Laboratorio de la Universidad de Sevilla y el instituto de la UNAM. ${ }^{5}$ Cabe agregar, además, que Bibliografía... inauguró una visualidad para las publicaciones del IAA por medio del diseño tipográfico a cargo de Vicente Nadal Mora (SCHAVELZON 2011), el formato rústico, sobrio y carente de ornamentación y la aparición del logo del IAA en la contratapa. Estos aspectos formales se encontrarán más involucrados con el proyecto historiográfico institucional recién desde la aparición de Anales y principalmente con relación al uso de planos y fotografías.

Aunque debe considerarse que el IAA se asentaba sobre la cátedra de Historia de la Arquitectura (segundo curso) que tenía a Buschiazzo como profesor titular y que, por lo tanto, la aparición de Bibliografía... contribuía como herramienta "en manos de los estudiantes y estudiosos para quienes fue

\footnotetext{
4 "Estaba preparada esta obra para su impresión, y escrito el prólogo que precede, cuando una circunstancia vino a dar un giro inesperado a su publicación. Después de muchos años de proponer a las autoridades la creación de un Instituto de Arte Americano similar a los varios que ya existen en diversos países de nuestro continente y en España, el dinamismo del arquitecto Julio V. Otaola, por ese entonces Delegado Interventor de la Facultad de Ciencias Exactas, Físicas y Naturales, hizo posible aquel propósito" (BUSCHIAZZO 1947, p. IX). ${ }^{5}$ Entre sus resoluciones constitutivas, el IAA consignaba una propuesta precisa de formatos característicos de los centros académicos: "Boletín [es], monografías, reimpresiones y en general, toda obra que encuadre dentro de su especialidad y de sus elevados propósitos" (EXPEDIENTE 16.594/46 1946, p. 1)
} 
creada" (BUSCHIAZZO 1947, p. IX), fue recién a inicios de los años cincuenta cuando comenzaron a incluirse progresivamente temas de arquitectura argentina y americana en la Facultad, con la apertura de la cátedra de Historia de la Arquitectura III (DE PAULA 1996-1997, p. 30). ${ }^{6}$ Por lo tanto, entendemos que la primera publicación del IAA tendió más a establecer un estado de la cuestión y a marcar un cambio de época estableciendo un corte respecto de lo producido hasta el momento, que a funcionar de manera exclusiva como material de consulta universitaria.

La selección del corpus incluido en Bibliografía... provenía de la propia biblioteca de Mario Buschiazzo. Esto que en el mismo prólogo podría ser visto como un gesto de modestia de su parte, cuando declaraba los límites que podría presentar su propio acervo, por otro lado tendía a reforzar su figura de especialista y el perfil de profesional abnegado que buscaba sostener. De este modo informaba al lector sobre su propio proceso de trabajo, un lector pensado como especialista y al mismo tiempo como colega:

Por otra parte, la recopilación ha sido hecha de mi biblioteca particular, que si bien pasa por ser excelente en su especialidad, no pretende tenerlo absolutamente todo. Bien sé que no faltarán quienes piensen que debí apartarme de esa comodidad pedante, pero conviene aclarar que este trabajo pesado y deslucido fué hecho robando horas al sueño y al margen de mis actividades habituales [...] (BUSCHIAZZO 1947, p. VII).

Otra cuestión fundamental se vincula a la reconsideración del arte colonial argentino que aportaba su emprendimiento. La intención de recomponer el panorama bibliográfico a partir de investigaciones basadas en nuevas perspectivas metodológicas se acompaña de la postulación de un objeto de estudio que hasta el momento había sido poco abordado por la historiografía artística. El arte del período colonial rioplatense no había ocupado un lugar preferencial en los trabajos de figuras precursoras como Martín Noel (18881963 ) y Ángel Guido (1896-1960), quienes dedicaron sus producciones escritas a otras áreas de Sudamérica, como Bolivia y el sur peruano, para sostener sus ideas sobre una "fusión" entre dos fuerzas potentes (NOEL 1915) y sobre un arte "mestizo" (GUIDO 1938).

Al revisar la recepción del libro entre los circuitos especializados, es justamente ese aspecto el que resultaba inédito para un área artística como la del Río de la Plata. Diego Angulo Iñiguez señalaba desde España: "[Buschiazzo] nos ofrece aquí un excelente repertorio como no lo posee ningún país latinoamericano de habla española, y que tan necesario sería sobre Méjico o el Perú, artísticamente más importantes que la Argentina" (D.A.I 1949, p. 361). Desde México, Manuel Romero de Terreros coincidía en apreciaciones similares: "Asombra verdaderamente el número de papeletas — más de ochocientas- que

\footnotetext{
${ }^{6}$ Sin embargo, ya en los planes de estudio de Historia de la Arquitectura de 1948, a su vez producto de la reestructuración curricular que acarreó la creación de la Facultad de Arquitectura en 1947, Buschiazzo comenzó a incluir temas de arquitectura argentina colonial y decimonónica como unidades separadas dentro del programa de la asignatura.
} 
ha reunido este crítico de arte, especialmente si se toma en consideración que la Argentina es, quizás, el país hispanoamericano donde abundan menos los monumentos de arte colonial" (ROMERO DE TERREROS 1949, p. 80).

Este conjunto de prejuicios sobre las artes rioplatenses, de menor rango que las del resto de los virreinatos, constituían una realidad para Buschiazzo y, al mismo tiempo, eran la base de su propuesta historiográfica, la de recuperar el patrimonio artístico argentino como objeto de estudio y volverlo susceptible de un análisis científico a partir del aporte de las fuentes documentales. Avanzados los años cuarenta, se encontraba claramente establecido dentro del campo historiográfico local quiénes eran los pioneros 0 , mejor dicho, quién era el pionero de los estudios artísticos coloniales. Noel, tempranamente incorporado a la Junta de Historia y Numismática Americana en 1918 y a cargo del plan orgánico de publicaciones de la Academia Nacional de Bellas Artes desde su creación en 1936, era la voz especializada al interior de instituciones diversas, universitarias y no universitarias, nacionales y transnacionales. Su enfrentamiento con Buschiazzo en 1948, motivado por las críticas a las publicaciones de la Academia Nacional formuladas desde Anales, fue un indicio clave del rol pionero que reivindicaba Buschiazzo y que lo condujo a defender de manera explícita su lugar de iniciador de los estudios sobre arte hispanoamericano (GUTIERREZ 1995; GARCIA 2016). La publicación de los Documentos de arte colonial argentino ${ }^{7}$ por parte de la Academia, que, como mencionamos, tenía a Noel como principal coordinador, era hasta ese momento el proyecto oficial más importante consagrado al tema y sobre el que Buschiazzo y su equipo desataron serios cuestionamientos con relación a la carencia de exhaustividad teórica. El reclamo de un rigorismo científico ausente hasta el momento, como mencionaba el prólogo de Bibliografía en $1947 \ldots$, afectaba doblemente a una tradición historiográfica no sólo pretérita, sino también en ejercicio, por lo que el libro constituye un antecedente significativo para entender los conflictos que comenzaban a desatarse alrededor de un objeto de estudio y el lugar particular que este comenzó a ocupar en esta etapa de profesionalización.

Los inicios del IAA estuvieron estratégicamente centrados en la consideración del arte colonial argentino, énfasis que puede advertirse en los artículos del primer número de la revista Anales y en los libros publicados posteriormente, como El arte de la imaginería en el Río de la Plata (RIBERA; SCHENONE 1948). La obra de Héctor Schenone (1919-2004), quien fuera secretario del IAA, y de Adolfo Ribera (1920-1990), ponía especial atención en establecer un estado de la cuestión en sintonía con las ideas expresadas por Buschiazzo en Bibliografía... El prólogo del libro evidenciaba la falta de producción escrita sobre escultura del período virreinal, al tiempo que presentaba la posición metodológica asumida por los autores: "el enfoque del tema es totalmente nuevo y hemos tropezado con una carencia absoluta de bibliografía" (RIBERA; SCHENONE 1948, p. 13); "debemos acudir a los archivos, en procura del documento veraz, con el propósito

\footnotetext{
7 Publicados desde 1939. En 1943 comenzaron a aparecer los Documentos de arte colonial sudamericano.
} 
de confrontarlo con las esculturas conservadas y con la tradición" (RIBERA; SCHENONE 1948, p. 14).

La especialización perseguida por el IAA y el enfoque continental señalado por Buschiazzo sobre "toda la parte sur de América" (BUSCHIAZZO 1962, p. 319), definía también una posición estratégica para diferenciarse del Instituto de Investigaciones Estéticas de la UNAM, conducido por Manuel Toussaint y centrado de manera casi exclusiva en los ejemplos artísticos novohispanos y modernos de México. Correspondería a los objetivos de otro artículo describir las variaciones en torno a la valoración del arte rioplatense por la historiografía artística, sobre todo porque el mismo Buschiazzo incurrió en apreciaciones cercanas a las de Angulo o a las de Romero de Terreros que hemos sintetizado más arriba. De hecho, su primer libro general sobre arquitectura colonial, Estudios de arquitectura colonial hispano americana (BUSCHIAZZO 1944), no incluyó edificios del Virreinato del Río de la Plata. No obstante, centrándonos en Bibliografía... y en las valoraciones realizadas por Buschiazzo sobre la producción de la primera mitad del siglo XX, este nuevo abordaje del arte argentino del período colonial puede ser entendido desde su dimensión estrictamente institucional y con relación a la postulación de nuevos propósitos historiográficos.

\section{La especificidad del formato en cuestión}

Los acervos bibliográficos de América Latina constituyeron un corpus sensible a los intereses culturales del período y los Estados Unidos jugaron un papel central en el desarrollo y centralización de colecciones en la Biblioteca del Congreso de Washington, la Unión Panamericana y la Universidad de Harvard, entre otros organismos. Así lo expresaba una fuente de la época, titulada "La importancia de la bibliografía en América", donde señalaba, respecto del país del norte, que "sus grandes posibilidades económicas, puestas al servicio del intercambio intelectual, han dado al mundo interesantísimos boletines, listas bibliográficas, catálogos y revistas, en las cuales nuestra producción intelectual, se halla prolijamente registrada" (TERÁN 1938, p. 7). Como explica Ricardo Salvatore, las bibliotecas norteamericanas en su afán de conformar colecciones con materiales y fuentes diversas sobre América Latina y consolidar la expansión norteamericana "en su momento de articulación neocolonial", debieron encarar en paralelo su difusión a través de formatos especializados, como bibliografías, directorios o boletines (SALVATORE 2006, p. 61). Como interés global, ello puede advertirse en diversos encuentros internacionales celebrados desde la década de 1930, como en una de las resoluciones de la VII Conferencia Internacional Americana del año 1933, donde se presentó un proyecto de resolución estimulando la producción de catálogos, guías de archivos y colecciones en cada uno de los países involucrados, con protocolos uniformes de compilación y catalogación y el establecimiento de un plan que asegurara el intercambio sistemático de informes entre bibliotecas y otros centros bibliográficos (SÉPTIMA CONFERENCIA INTERNACIONAL AMERICANA 1933, p. 47). Lo mismo sucedió en la Conferencia Interamericana de Consolidación de la Paz celebrada en 1936, donde la Delegación Argentina de la Comisión Internacional de Cooperación 
Intelectual postuló la necesidad de un boletín trimestral que reuniera el total de las publicaciones del continente para su posterior puesta en circulación entre los diferentes Estados americanos, propósito que iba en sintonía con el "panamericanismo espiritual" que impulsaba esas iniciativas (CONFERENCIA INTERAMERICANA DE CONSOLIDACIÓN DE LA PAZ 1937, p. 579). Durante la celebración del II Congreso Internacional de Historia de América celebrado en Buenos Aires en 1937, el historiador Clarence H. Haring, que oficiaba como delegado de los Estados Unidos, puso el acento en el proyecto de recopilación bibliográfica conducido por un comité central que comenzaba a publicar "manuales" sobre estudios latinoamericanos. Estos manuales, denominados Handbook of Latin American Studies y editados por el hispanista Lewis Hanke, se orientaban a "integrar la investigación de los campos adyacentes o marginales, bajar las barreras que separan los campos académicos convencionales, y acentuar la unidad en el estudio de la cultura hispanoamericana (ACADEMIA NACIONAL DE LA HISTORIA 1938, p. 43).

Fue en ese contexto inmediato donde se ubicó el antecedente más cercano a Bibliografía..., en una breve recopilación realizada por Martín Noel titulada "La historia del arte en Sud América durante el período colonial" (NOEL 1938) e incluida en la colección Handbook of Latin American Studies mencionada en la intervención de Haring. Esta colección, interesada de forma integral en las humanidades de América Latina en temas de arte, folclore, educación, historia, entre otras, constituía una guía anual de las principales publicaciones en las áreas mencionadas y contenía introducciones generales que antecedían el listado de obras. En su participación, Noel incluyó un primer listado orientado a los estudios generales del tema, para luego discriminar por áreas geográficas las publicaciones más significativas de cada uno de los cuatro grupos que organizó: Venezuela, Colombia y Panamá; Ecuador, Perú y Bolivia; Argentina, Chile y Uruguay; y el Brasil. La parcialidad operante en la presentación, basada en criterios puramente geográficos, era consecuente con la elección de las publicaciones, que, además de no resultar exhaustiva, no adquiría una organización uniforme y sus comentarios se acercaban más a adulaciones sobre las obras y autores seleccionados que a verdaderas notas críticas.

El reconocimiento de ese escenario por parte de Buschiazzo, que contaba con una previa inserción profesional en los Estados Unidos, se confirmaba en el prólogo de Bibliografía..., donde mencionaba su visita a Washington en el año 1941 en el boceto del libro que se publicaría seis años más tarde. De acuerdo al autor, ese boceto habría funcionado como modelo para un proyecto paralelo que denomina "Bibliografía de Arte de la América Latina" y que se publicó como Guide to the Art of Latin America por la Fundación Hispánica de la Biblioteca del Congreso de Washington, siendo sus editores los historiadores Robert Smith y Elizabeth Wilder (1948). Esta guía, que se presentaba a sí misma como una elaboración pionera, aspiraba a una clasificación general de la literatura artística partiendo de las publicaciones más generales, para luego apartarlas por disciplinas, a saber; Arquitectura, Artes Menores, Pintura, Escultura y, en algunos 
casos, Artes Gráficas y Educación e Instituciones Artísticas. En el mismo prólogo de dicha obra, los editores reconocían especialmente a Mario Buschiazzo por su "conocimiento bibliográfico" y destacaban, al interior del apartado dedicado a la Argentina, el carácter imprescindible de sus investigaciones.

Buschiazzo había obtenido un subsidio de la American Federation of Learning Societies para una misión de intercambio cultural entre enero y abril de 1941 y, en 1960, le fue concedida la beca Rockefeller para investigar en las universidades de Ann Arbor, Michigan, Austin y Texas (BIO-BLIOGRAFÍA s/f). Durante su primer viaje a Estados Unidos, junto a otros líderes "de las artes y de la educación" (OFFICE OF PUBLIC COMMUNICATION 1941), brindó numerosas conferencias sobre arte del período colonial y reflexionó puntualmente sobre la dimensión historiográfica del área de estudios, haciendo explícita su actualización bibliográfica $y$, solapadamente, su perfil de especialista:

In your own country there is an important group of investigators and professors have carried out a splendid work. In the first place there is Rexford Newcomb, the Dean of the School of Fine Arts in Illinois [...] then there is a whole series of writers who have devoted themselves to Mexican Art; among them I must mention Sylvester Baxter, Atlee B. Ayres, Chase, Anita Brender, Spratling, George Wharton James, etc. Recently, the Taylor Museum of Colorado Springs, has published a magnificent book by the Professor of Yale University, Mr George Kubler, on religious architecture in New Mexico, in which he makes a careful study of all the details of that art (BUSCHIAZZO 1941, p. 1). ${ }^{8}$

Su intención de fortalecer los lazos con Estados Unidos se afianzó una vez establecido el IAA. Este interés se tornaba explícito, por ejemplo, en su correspondencia con Lewis Hanke, quien asentía ante la sugerencia del argentino de concretar intercambios bibliográficos:

We were delighted to learn of the new and important developments in the Instituto de Investigaciones Estéticas, and of your important role as Director of this institution. I am transmitting your letter to the Hispanic Exchange and Gift Division, which will do all in its power, I know, to see that the Hispanic publications of the Library of Congress are sent to the Library of your Instituto (HANKE 1948)..$^{9}$

Estos vínculos tuvieron una continuidad en el área de las publicaciones, ${ }^{10}$ lo que favoreció la posición del organismo como núcleo de reunión de los estudios

\footnotetext{
${ }^{8}$ En su propio país hay un importante grupo de investigadores y profesores que han realizado un trabajo espléndido. En primer lugar, Rexford Newcomb, decano de la Escuela de Bellas Artes en Illinois [...] hay toda una serie de escritores que se han dedicado al arte mexicano; entre ellos debo mencionar a Sylvester Baxter, Atlee B. Ayres, Chase, Anita Brender, Spratling, George Wharton James, etc. Recientemente, el Museo Taylor de Colorado Springs ha publicado un magnífico libro del profesor de la Universidad de Yale, George Kubler, sobre arquitectura religiosa en Nuevo México, en el cual hace un cuidadoso estudio de todos los detalles de ese arte (Traducción del autor).

${ }^{9}$ Estuvimos encantados de conocer los nuevos e importantes desarrollos en el Instituto de Investigaciones Estéticas y de su importante papel como Director de esa institución. Transmitiré su carta a la Sección Hispánica de Intercambio y Donaciones que hará todo lo que esté a su alcance, lo sé, para que las publicaciones hispánicas de la Biblioteca del Congreso se envíen a la biblioteca de su Instituto" (Traducción del autor).

${ }_{10} \mathrm{Al}$ interior del "principio de vertebración universitaria panamericana" (BUSCHIAZZO 1949, p. 9) sostenido por Buschiazzo, cabe señalar la visita del historiador norteamericano Kenneth Conant a la Facultad de Arquitectura en 1947 y la posterior edición por parte del IAA de sus conferencias dictadas en Buenos Aires en
} 
sobre arte colonial sudamericano. En 1956, el IAA publicó La pintura del siglo XVI en Sud América, de Martin Soria (1956), historiador de origen alemán radicado en Estados Unidos. El libro contó con el apoyo financiero de la Fundación Guggenheim, de la cual Soria era becario, y la misma situación se repitió con la edición de Historia de la pintura cuzqueña, de los bolivianos José de Mesa y Teresa Gisbert (1962) años más tarde. En su correspondencia con Henry Allen Moe, presidente de la mencionada fundación, Buschiazzo expresaba su interés en la conformación de un "fondo editorial John Simon Guggenheim" para la edición de obras de cultura bajo el patrocinio de este Instituto" (BUSCHIAZZO 1956 , p. 1). Si bien esto no sucedió, la experiencia, como señalamos, se repitió con el libro de Mesa y Gisbert.

A partir de los antecedentes revisados, creemos que Bibliografía... debería considerarse como un punto de partida significativo para el proyecto de difusión del arte de América Latina sostenido por Buschiazzo desde su propio instituto. El libro, además de presentar un formato inédito para el ámbito local y resultar oportuno para definir un proyecto historiográfico, trazaba una estrategia institucional que favorecía la definición del IAA como espacio especializado en un contexto transnacional interesado por el arte latinoamericano y sus publicaciones.

\section{Un ejercicio de crítica bibliográfica}

Bibliografía... adoptó un marco temporal que excede, pese a la exactitud de su título, el período estrictamente colonial. Buschiazzo justificó esta decisión por la imposibilidad de establecer un corte exacto, debido a que la "evolución de nuestras artes virreinales continuó desarrollándose durante los primeros años de la vida republicana" (BUSCHIAZZO 1947, p. VIII), sobre todo, señalaba, en las "artes menores", que, iniciadas en la colonia, continuaron a lo largo del siglo XIX. Esta apertura cronológica iba de la mano, entonces, de la reconsideración de estudios sobre objetos diversos, como textiles, mobiliario y orfebrería, a los que el libro le dedicaba una sección específica. Las secciones de arquitectura y escultura eran las que respondían de modo más ajustado al título del libro, mientras que la de pintura, por ejemplo, incluía obras sobre Prilidiano Pueyrredón, Carlos Morel, Carlos Pellegrini y León Pallière, evidenciando un desajuste en las decisiones tomadas por Buschiazzo respecto de lo que consideraba en un sentido estricto "arte colonial argentino". La decisión de mantener, pese a la inexactitud cronológica, el nombre de la obra enfocado en el período colonial, fortalece nuestros supuestos sobre la necesidad de Buschiazzo de producir un balance sobre un área de estudios específica, generando al mismo tiempo una mayor conexión con el nombre de la institución editora: Instituto de "Arte Americano".

La organización general del libro partía de dos divisiones principales: la primera se titulaba "Obras de historia del arte argentino" y estaba repartida a su vez en 11 secciones: "Bibliografía", con ediciones como los Handbook... y la Bibliografía de arte español y americano, de Matilde López Serrano; 
"Concepto, crítica e interpretación", en la que predominaban libros y artículos de Ángel Guido y Martín Noel; "Historia general del arte argentino"; "Historia parcial del arte argentino", referida a trabajos monográficos; "Historia de la arquitectura"; "Historia de la escultura"; "Historia de la pintura"; "Historia de las artes menores"; "Material de ilustración"; "Documentos de historia del arte argentino", conformada por mapas y planos arquitectónicos; y una "Miscelánea" con algunos folletos y artículos de prensa periódica. La segunda sección, "Materiales documentales para la historia del arte argentino", se subdividía en cinco apartados: "Recopilaciones documentales"; "Obras generales y trabajos monográficos de historia argentina"; "Recuerdos, tradiciones, descripciones y viajeros"; "Catálogos de colecciones, salones, guía de museos, etc." y una miscelánea final que, al igual que la anterior, reunía fuentes de procedencias diversas. Todas las obras se encontraban numeradas como "fichas" de forma consecutiva, completando un total de 843.

La intervención de Buschiazzo en gran parte de las fichas en la forma de acotaciones aclaratorias o ampliatorias, constituye el aspecto más relevante del libro. Sobre el Palliére de Alejo González Garaño, comentaba: "para el arte colonial interesan algunas de las acuarelas porque reproducen aspectos antiguos de la ciudad, faroles, rejas, etc." (BUSCHIAZZO 1947, p. 43). Algo similar decía de un artículo del mismo autor en el diario La Prensa: "es el estudio más completo que se ha publicado sobre los monumentales peinetones de carey usados a comienzos del siglo XIX" (BUSCHIAZZO 1947, p. 54). En otros casos,

20 sus palabras eran más críticas y tendían a justificar su inclusión en la selección realizada, y en otros, desacreditaban por completo el material en cuestión. Veamos algunos casos: respecto de El arte en la América española, de Noel, decía: "Obra superficial, de divulgación. Tiene un capítulo sobre el nacimiento y desarrollo de los estilos coloniales, otro sobre pintura, escultura y artes suntuarias y un tercero sobre el arte en el Río de la Plata" (BUSCHIAZZO 1947, p. 7). Sobre La arquitectura colonial en Hispanoamérica, de Mario Busaniche, determinaba: "La mayoría de los datos publicados por este autor, provienen del libro del Padre Furlong titulado Glorias Santafecinas, y del folleto del autor de esta bibliografía que se registra bajo el número 69" (BUSCHIAZZO 1947, p. 19). Esta actitud correctiva también aparecía con Síntesis histórica del templo de Nuestra Señora del Pilar, de Enrique Udaondo: "Estudio del templo y convento de los franciscanos recoletos [...] Atribuye la estatua de San Pedro de Alcántara al escultor Alonso Cano, pero sin documentarlo. Esta atribución es hoy en día negada por la mayoría de los investigadores" (BUSCHIAZZO 1947, p. 23). El caso más determinante fue el de "L'art dans I 'Amérique latine" de Louis Gillet, donde sentenciaba, sin dar mayores detalles: "Contiene una serie de errores garrafales. Sólo se le puede disculpar por tratarse de la primera gran historia del arte en que se ocupan de América" (BUSCHIAZZO 1947, p. 7).

Otras consideraciones, por el contrario, eran muy positivas. Como el caso de la obra pionera de Juan Kronfuss (1872-1944), Arquitectura colonial en Argentina: 
Aun cuando muchos de los datos de esta magnífica obra actualmente se han ratificado, es justo reconocer que se trata de la mejor publicación escrita hasta la fecha sobre arquitectura colonial. Los relevamientos, dibujos y acuarelas hechos «in situ» por el autor son de gran valor documental. A este debe agregarse el mérito de haberse publicado cuando nadie estudiaba nuestras artes pretéritas (BUSCHIAZZO 1947, p. 19).

La revaloración de Kronfuss y el enfático rescate de su obra en el contexto del libro respondían a un propósito mayor. Como hemos mencionado en otros trabajos (GARCÍA 2013), la defensa que hacía Buschiazzo del arquitecto húngaro como pionero debido a su temprano estudio in situ de la arquitectura del interior del país, le permitía establecer un vínculo con las "nuevas generaciones de estudiosos" (BUSCHIAZZO 1946, p. 11) formadas al interior de su instituto. En su discurso, las situaba como continuadoras de una tradición reciente, pero a la que aportaban, como mencionamos, el estudio de las fuentes directas. Resulta llamativo que sobre los Documentos de arte argentino, publicados por la Academia Nacional de Bellas Artes y principal blanco de críticas de los primeros números de Anales, no realizaba demasiados reparos; sólo destacaba su tendencia monográfica y los ubicaba bajo el rótulo de "historia parcial del arte argentino".

Aun así, la actitud crítica que adoptó Buschiazzo y su renuncia a la elaboración de un mero registro por categorías, establecía un antecedente elemental en tanto espacio preparatorio de las "Notas bibliográficas" que la revista Anales comenzó a publicar como sección fija desde su primer número en 1948. Dicha sección instaló por primera vez en la historiografía local un espacio de revisión constante sobre las producciones de arte colonial en el ámbito transnacional, evidenciando al mismo tiempo los modelos metodológicos a los cuales el IAA adhería y de los cuales se encontraba completamente alejado. A su vez, Buschiazzo había mostrado su inclinación al comentario bibliográfico con sus participaciones fijas en la sección "Bibliografía" del Boletín de la Comisión Nacional de Museos y de Monumentos y Lugares Históricos desde su primer tomo (1939), donde participaba junto a José Torre Revello. Siguiendo la línea de este artículo, una de sus intervenciones más destacables en el boletín y contemporánea a Bibliografía... es la que escribió sobre el catálogo de la Exposición de Arte Religioso Retrospectivo realizada en el año de 1941 en el Museo Histórico Provincial de la ciudad de Santa Fe, cuyo texto principal firmaba Ángel Guido:

El estudio preliminar, a cargo del arquitecto Ángel Guido, se diluye en las conocidas y personalísimas teorías del autor, sin aportar mayores datos respecto de las obras expuestas. La misma clasificación de los objetos exhibidos es a veces arbitraria e infundida. Hacemos notar esto por cuanto seguimos creyendo que, antes de lanzarnos a teorizar sobre arte americano, es necesario proceder a una prolija y seria investigación sobre autores, procedencia, cronología, clasificación, etc. de las piezas artísticas, labor que aun no se ha hecho en nuestro país con respecto a la pintura y escultura coloniales (M.J.B 1942, p. 648) 


\section{Conclusión}

Un pueblo sin inventarios bibliográficos es un pueblo sin conciencia de sí mismo, y es un pueblo incapaz de orientar a los suyos por los caminos del progreso Guillermo Furlong (1954 apud ZABALA; FERNANDEZ 2000, p. 4).

El epígrafe de Furlong retrataría, en el sentido que persigue este artículo, el modo en que las bibliografías responden a un proyecto mayor que el de un simple repertorio y aportan una orientación de sentido a la producción cultural que seleccionan y organizan. En el caso que hemos revisado, Buschiazzo persiguió la posibilidad de poner en evidencia la diversidad de formatos provistos en un campo disciplinar aún no especializado y explicitó sus debilidades desde el inicio, denunciando desde el prólogo la ausencia de "rigorismo científico" como problema global de los estudios artísticos.

En segundo lugar, y a partir de lo que hemos observado hasta aquí, consideramos que Bibliografía... constituyó una práctica de intervención crítica propia del campo académico a través de un formato particular que Buschiazzo utilizó como herramienta para seleccionar y establecer un orden, detentando al mismo tiempo el poder y la capacidad de un experto. En este sentido, el libro debería ser estimado al interior de un proceso de especialización de la historiografía artística en el país, en el cual la revista Anales tuvo un rol central como espacio de continua revisión de esa escritura desde un formato 22 especializado. Bibliografía... preparó las condiciones para la aparición de Anales en el contexto local y Buschiazzo hizo uso de un instrumento ventajoso para establecer un balance, determinar las insuficiencias e instalar la necesidad de nuevos abordajes que serían provistos por su reciente instituto.

\section{Referencias bibliográficas}

ACADEMIA NACIONAL DE LA HISTORIA. II Congreso Internacional de Historia de América. Buenos Aires: Peuser, 1938.

ANGULO IÑIGUEZ, Diego. BUSCHIAZZO (Mario): Bibliografía de arte colonial argentino, Buenos Aires, 1947, 150 p. (Reseña). Archivo Español de Arte, n. 88, p. 361, 1949.

BIO-BLIOGRAFÍA DE MARIO BUSCHIAZZO. [s.f.]. Archivo de la Academia Nacional de Bellas Artes.

BURUCUA, José E. Historiografía artística argentina. En: BURUCÚA, José E. (Dir.). Nueva historia argentina. Arte, sociedad y política. Buenos Aires: Sudamericana, 1999. ; TELESCA, Ana M. El arte y los historiadores. En: La Junta de Historia y Numismática Americana y el movimiento historiográfico en la Argentina. 1893-1938. Buenos Aires: Academia Nacional de la Historia, 1996, p. 225-238. t. III. 
BUSCHIAZZO, Mario. El Instituto de Arte Americano de la Facultad de Arquitectura y Urbanismo. Revista de la Universidad de Buenos Aires, V época, año VII, n. 2, p. 318-322, 1962.

. Carta a Henry Allen Moe. Buenos Aires, enero 12 de 1956. Archivo de la familia Buschiazzo.

. Prólogo. En: CONANT, Kenneth. Arquitectura moderna en los Estados Unidos. Buenos Aires: Instituto de Arte Americano e Investigaciones Estéticas, 1949, p. 7-9.

. Bibliografía de arte colonial argentino. Buenos Aires: Instituto de Arte Americano e Investigaciones Estéticas, 1947.

Prólogo. En: FURLONG, Guillermo. Arquitectos argentinos durante la dominación hispánica. Buenos Aires: Huarpes, 1946, p. 7-11.

Estudios de arquitectura colonial hispano americana. Buenos Aires: Guillermo Kraft, 1944.

Indian influence on the colonial architecture of Latin America, 1941. Mimeo, archivo de la familia Buschiazzo.

Bio-bibliografía de Mario Buschiazzo. [s.f.]. Carpeta "Mario Buschiazzo", Archivo de la Academia Nacional de Bellas Artes.

CONFERENCIA INTERAMERICANA DE CONSOLIDACIÓN DE LA PAZ. Diario de Sesiones (versiones taquigráficas). Buenos Aires: Imprenta del Congreso Nacional, 1937.

DE CERTEAU, Michel. La escritura de la historia. México: Universidad Iberoamericana, 2008 [1973].

- La invención de lo cotidiano 1 . Las artes del hacer. México: Universidad Iberoamericana, 2000 [1990].

DE MESA, José; GISBERT, Teresa. Historia de la pintura cusqueña. Buenos Aires: Instituto de Arte Americano e Investigaciones Estéticas, 1962.

DE PAULA, Alberto. Mario J. Buschiazzo y el Instituto de Arte Americano. Anales del Instituto de Arte Americano e Investigaciones Estéticas "Mario J. Buschiazzo", n. 31-32, p. 15-71, 1996-1997.

EL DIRECTOR. Presentación. Anales del Instituto de Arte Americano e Investigaciones Estéticas. Buenos Aires: Instituto de Arte Americano e Investigaciones Estéticas, 1948, p. 1-8.

FURLONG, Guillermo. Una tarea impostergable (la compilación de bibliografías argentinas). El Pueblo, p. 4, 13 de abril de 1954.

GARCIA, Carla Guillermina. La recuperación del patrimonio artístico como proyecto historiográfico en los inicios del Instituto de Arte Americano e Investigaciones Estéticas. En: Congreso Regional de Historia e Historiografía, V. Actas... Santa Fe: Universidad Nacional del Litoral, 2013 [CD-ROM]. 
. "Los fósiles de la Academia." Martin Noel, Mario Buschiazzo y los itinerarios institucionales de la historiografía artística argentina. Caiana. Revista de Historia del Arte y Cultura Visual del Centro Argentino de Investigadores de Arte, n. 9, p. 54-70, 2016.

GEOGHEGAN, Abel. Obras de referencia de América Latina. Buenos Aires: edición del autor, 1965.

GORELIK, Adrián; SILVESTRI, Graciela. "Lo nacional" en la historiografía de la arquitectura en la Argentina: el peso de una tradición. Historiografía argentina 1958-1988: una evaluación crítica de la producción histórica nacional. Buenos Aires: Comité Internacional de Ciencias Históricas, 1990, p. $174-185$.

GUIDO, Ángel. El estilo mestizo o criollo en el arte de la colonia. En: Congreso Internacional de Historia de América, II. Actas... Buenos Aires: Academia Nacional de la Historia, 1938, p. 475-494. t. III.

GUTIERREZ, Ramón. "La polémica Noel-Buschiazzo". En: GUTIERREZ, Ramón et. al. El arquitecto Martín Noel. Su tiempo y su obra. Sevilla: Junta de Andalucía, 1995, p. 237-246.

HANKE, Lewis. Carta a Mario Buschiazzo. Washington, 14 de febrero de 1948. Archivo del Instituto de Arte Americano e Investigaciones Estéticas "Mario J. Buschiazzo, Facultad de Arquitectura, Diseño y Urbanismo, UBA.

24 M.J.B., Museo Histórico Provincial. Exposición de Arte Religioso Retrospectivo, Coronación de la Virgen del Rosario; Santa Fe, 1941, 60 p. de texto + 122 p. de ilustraciones + (32) p. de catálogo. Prólogo de Julio Marc. Texto de Ángel Guido. Boletín de la Comisión Nacional de Museos y de Monumentos y Lugares Históricos. Buenos Aires, 1942, p. 648. t. 4.

NOEL, Martin. Comentarios sobre el nacimiento de la arquitectura hispanoamericana. Revista de Arquitectura, n. 1, p. 8-13, 1915.

. La historia del arte en Sud América durante el período colonial. In: . Handbook of Latin American Studies. Cambridge: Harvard University Press, 1938, p. 505-527.

PENHOS, Marta. De categorías y otras vías de explicación: una lectura historiográfica de los Anales de Buenos Aires (1948-1971). En: Encuentro Internacional sobre Barroco, III. Actas... La Paz: Fundación Visión Cultural, 2005, p. 167-174.

RIBERA, Adolfo; SCHENONE, Héctor. El arte de la imaginería en el Río de

la Plata. Buenos Aires: Instituto de Arte Americano e Investigaciones Estéticas, 1948.

ROMERO DE TERREROS, Manuel. Mario J. Buschiazzo: Bibliografía de arte colonial argentino, Buenos Aires, 1947. Anales del Instituto de Investigaciones Estéticas, v. V, n. 17, p. 80, 1949. 
SALVATORE, Ricardo. Textos e imágenes: reproducción. En: SALVATORE, Ricardo. Imágenes de un imperio. Estados Unidos y las formas de representación de América Latina. Buenos Aires: Sudamericana, 2006, p. 57-75.

SCHÁVELZON, Daniel. Historia de papel y tinta. Los tapas de Anales y los libros del Instituto de Arte Americano. Anales del Instituto de Arte Americano e Investigaciones Estéticas "Mario J. Buschiazzo", n. 41, p. 235-237, 2011.

SÉPTIMA CONFERENCIA INTERNACIONAL AMERICANA. Sesiones plenarias. Actas y antecedentes. Montevideo: Imprenta Nacional, 1933.

SORIA, Martin. La pintura en el siglo XVI en Sudamérica. Buenos Aires: Instituto de Arte Americano e Investigaciones Estéticas, 1956.

SMITH, Robert; WILDER, Elizabeth (Ed.). Guide to the Art of Latin America. Washington: Hispanic Foundation, The Library of Congress, 1948.

TERÁN, Enrique. La importancia de la bibliografía en América. En: Mensaje, p. 5-10, mayo 1938,.

OFFICE OF PUBLIC COMMUNICATION. Visit to the United States of leaders in the professions, the arts, and education. The Department of State Bulletin, v. IV, n. 82, p. 96, 1941.

ZABALA, Horacio; FERNANDEZ, Oscar. Bibliografía de biografías argentinas. Buenos Aires: Sociedad Argentina de Información, 2000. 